\title{
Policy report on helium proposes long-term solutions
}

\author{
www.aps.org/policy/reports/popa-reports/upload/HeliumReport.pdf \\ https://conserve-helium.org
}

$\mathrm{H}$ elium $(\mathrm{He})$ is a nonrenewable natural resource with an uncertain future. The lightest of the noble gases, helium is unique because it is a liquid at ultralow temperatures (approaching absolute zero Kelvin), which makes it essential in cryogenic applications that are used in a broad range of materials, physics, and chemistry research as well as for other ultralow temperature experiments.

This important resource is the topic of a recent policy report released by the Materials Research Society (MRS) in conjunction with the American Physical Society (APS) and the American Chemical Society (ACS). The report, "Responding to the U.S. Research Community's Liquid Helium Crisis," summarizes the past and continued role of liquid helium in US innovation, describes the cost and availability challenges faced by researchers dependent on liquid helium, provides a methodology for scientists to evaluate the feasibility of various helium recycling options, and presents a set of five policy recommendations for the executive and legislative branches of government as well as the relevant professional societies.

"The irreplaceable nature of liquid helium within the research community has galvanized the MRS and partner societies to focus on some long-term solutions," says Damon Dozier, MRS Director of Government Affairs. Citing the looming closure of the Federal Helium Reserve and transition to a private market in 2021 (set in motion by the Helium Stewardship Act-Pub. L. 113-40 - and reported in the December 2013 issue of MRS Bulletin), Mark Elsesser, a senior policy analyst at APS, says, "we need to act now so that when 2021 comes we are prepared, and as a community are less dependent on the helium market."

These sentiments are echoed across the range of helium users, many of whom have already seen steep price hikes and shortages of liquid helium over the last five years. Sophia Hayes, a professor in the Department of Chemistry at Washington University, says, "The price I paid for liquid helium was fairly stable up to 2012, then prices started to rise. By the fall of 2013 the price had more than doubled and by the fall of 2015 it had almost reached three times the amount I was paying in 2012."

Hayes considers herself "one of the lucky ones" because Washington University is a large university with a degree of purchasing power and has also started to help subsidize liquid-helium costs for its researchers - a luxury most helium users do not have. The report points out that the drastic helium price increase experienced by Hayes is not uncommon among liquid-helium users, and the price paid for liquid helium can vary significantly between users, even in the same region and with similar consumption. Indeed, no correlation could be found between liquid-helium price and location or consumption levels (see figure).

"I have very strong concerns about how I'm going to keep my research going under these conditions because I can't predict how helium price is going to fluctuate," says Hayes, who conducts materials chemistry research using solidstate nuclear magnetic resonance (NMR) to probe structure and electronic properties of semiconductors, metal oxide thin films, and materials for carbon capture. She uses liquid helium both to sustain superconducting magnets in her laboratory - a fixed use, and to conduct NMR studies at cryogenic temperatures - a variable use. "When the price of helium goes up, it has to come out of some other part of the budget, so where we can, we take it out of our summer salaries or, if necessary, out of the budget for graduate students," Hayes says, referring to herself and other colleagues within the liquid-helium community. "But sometimes even that is not enough and we end up having to terminate variable use experiments or shut down important equipment," Hayes says.

Unfortunately, cost increases are not the only challenge faced by the helium research community. Supply issuesboth availability and unreliable delivery schedules-plague researchers. According to Bill Halperin, a professor of physics at Northwestern University, liquid-helium supply is similar to air travel because "with flying there are only a small number of airlines and it is in the interest of the airline to overbook and bump passengers where necessary. Similarly, there are only a small number of liquid-helium providers, and it is also in their interest to overbook." Halperin added that small users are often the first to see their supply disrupted, but also emphasized that even large users are in danger of supply droughts if demand becomes much greater than supply.

One of the most severe consequences of rising prices and uncertain supply is the forced shutdown of cryogenic (fixed helium usage) equipment. Without a steady supply of liquid helium the equipment warms above a threshold temperature, which often means it will be permanently decommissioned according to Hayes, who explained with this analogy:

Operating equipment that depends on a fixed supply of liquid helium, I am like a cattle rancher. If the rancher doesn't have water, the cattle die. Therefore, without water, the rancher's livelihood is lost. And after even a very short period without water, there may be a "point of no return." The same is true for me, and other researchers, who depend on cryogenic equipment. Without liquid helium our superconducting magnets will cease to function and may sustain 
permanent damage, making restarting this equipment after shuttering it both extraordinarily expensive and sometimes physically impossible.

A second consequence of the difficult helium situation that is somewhat harder to quantify is the loss in both researchers and innovation. "When students see the lengths I have to go through to pay for helium, they are naturally reluctant to continue in a field that looks like a constant struggle for funding," Hayes says. And Halperin adds that "it's not only students that are being driven away from helium-based research, it's also young faculty and some established researchers. It's hard to be dependent on a resource that fluctuates so much in price and availability."

A near-term solution that has already had an impact for small helium users is the Liquid Helium Purchasing Program $\left(\mathrm{LHeP}^{2}\right)$. Established by the Defense Logistics Agency (DLA) in partnership with APS and ACS, LHeP² acts as a brokerage that procures liquid helium on behalf of federally funded researchers. Detailed within the report and in the September 2014 issue of MRS Bulletin, this program drastically increases the purchasing power of its enrollees and provides for greater stability in both price and delivery with average reported savings of $15 \%$.

But as the report points out, "Earth's irreplaceable helium resources continue to be depleted and reducing our longterm use of helium is vital." Two main long-term solutions to conserve helium within the research field are proposed in the report-reducing helium usage with advanced closed-cycle systems and recycling helium by capturing and reliquefying it. Unfortunately, both of these options come with a hefty price tag and the capital investment to purchase closed-cycle or recycling systems is the primary barrier to adoption of these conservation methods.

While capital investment is a significant hurdle, it is not insurmountable. "At the moment, we can afford the cost of liquid helium, but we know that may not always be the case. We needed to prepare for the future, so we bought a new liquefier last year with money borrowed from the University," Halperin says. He

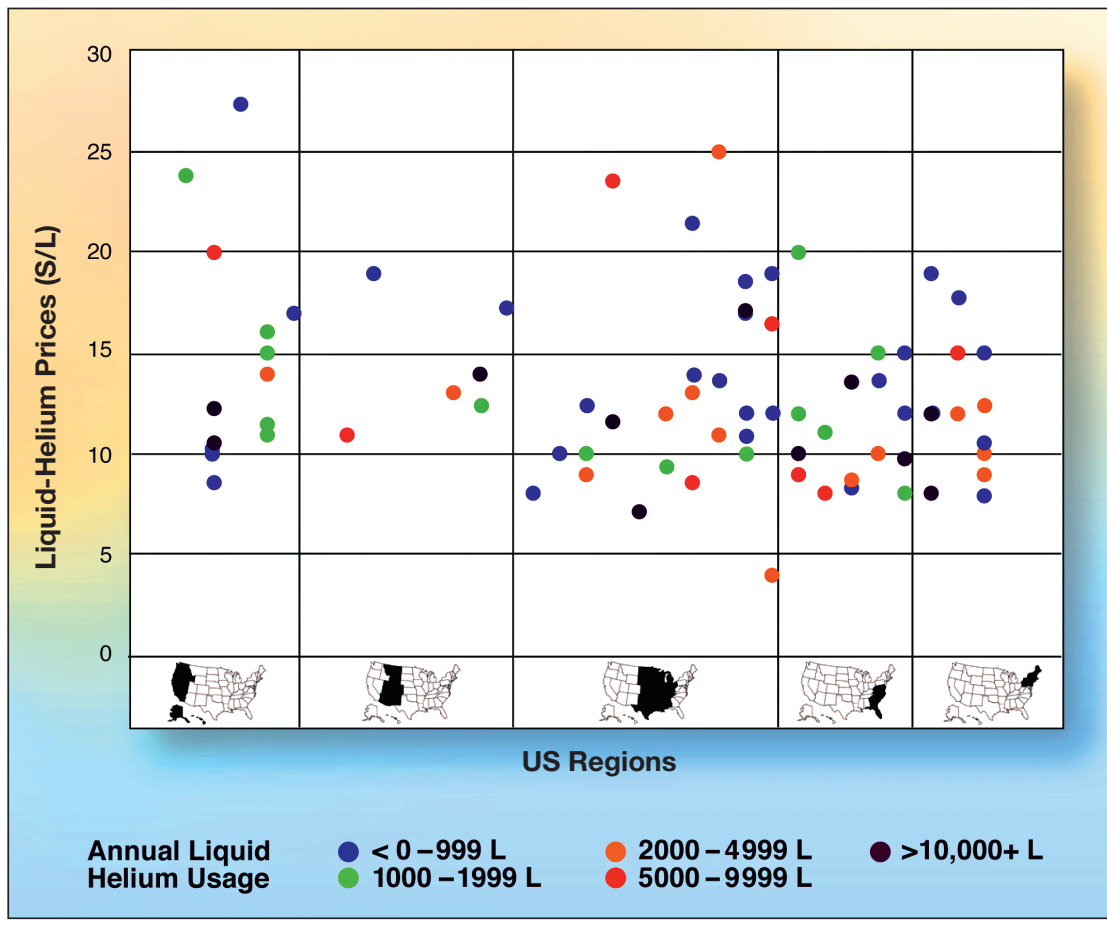

Liquid-helium prices for 2014-2015 from more than 70 US institutions grouped into five regions, showing no correlation with location or consumption. Each marker represents pricing and consumption data from user(s) at a single institution. Courtesy of the American Physical Society, Materials Research Society, and American Chemical Society.

adds, "the amount we are already saving on liquid-helium costs covers the loan payment and as the price of helium rises, this equipment will buffer us from the expense." Hayes echoed Halperin's sentiments and said she is in the process of trying to procure a helium conservation system for her laboratory. She likened having helium recycling capabilities to getting a Prius, saying, "you will always need some helium, but changes in pricing won't have as big an impact."

The report is a good place for helium users to start looking for solutions because it details examples of cost-effective investments in helium conserving systems, points out a government program run by the National Science Foundation's Division of Materials Research that is helping some researchers purchase helium recycling equipment, mentions alternative financing options offered by manufactures of helium conserving equipment, and provides a method by which scientists can evaluate the feasibility of various helium conservation options for their own laboratories. "The hope is that this report will catalyze scientific helium users to discover and implement a variety of ways to become less dependent on the helium market," Dozier says.

To compliment the information within the report, APS has launched a website where researchers can explore various helium conservation options available to them and be matched directly to the manufacturers of helium recycling and liquefying systems. "The website is a response to the final recommendation within the report for scientific societies to play a role in helping researchers determine if it is economically feasible to upgrade their labs, and to connect them with the right people from the manufacturing side," Elsesser says. "We want to encourage both our international and domestic membership to take advantage of this website," added Dozier, who explained that the report and website are both ways professional societies are trying to "be part of the solution" and ensure helium remains accessible for research in the long term.

Jennifer A. Nekuda Malik 


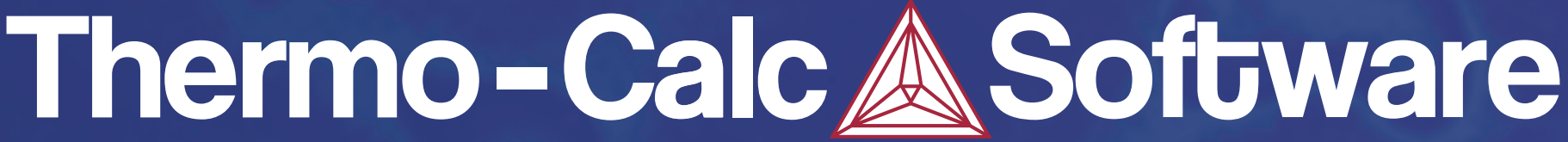

Powerful Software for Thermodynamic and Diffusion Calculations

\section{Software:}

$\checkmark$ Thermo-Calc for thermodynamics and phase equilibria in multicomponent systems

$\checkmark$ Diffusion module (DICTRA) for diffusion controlled transformations

$\checkmark$ Precipitation module (TC-PRISMA) for precipitation kinetics

$\checkmark$ Software development kits for linking Thermo-Calc to your own software codes

$\checkmark$ Over 30 Databases for thermodynamic and mobility applications

\section{Benefits:}

$\checkmark$ Predict which phases will form as a function of composition, temperature

$\checkmark$ Reduce costly, time-consuming experiments

$\checkmark$ Base decisions on scientific data

$\checkmark$ Shorten development time

$\checkmark$ Accelerate development while reducing risk

$\checkmark$ Improve the quality and consistency of your products through deeper understanding
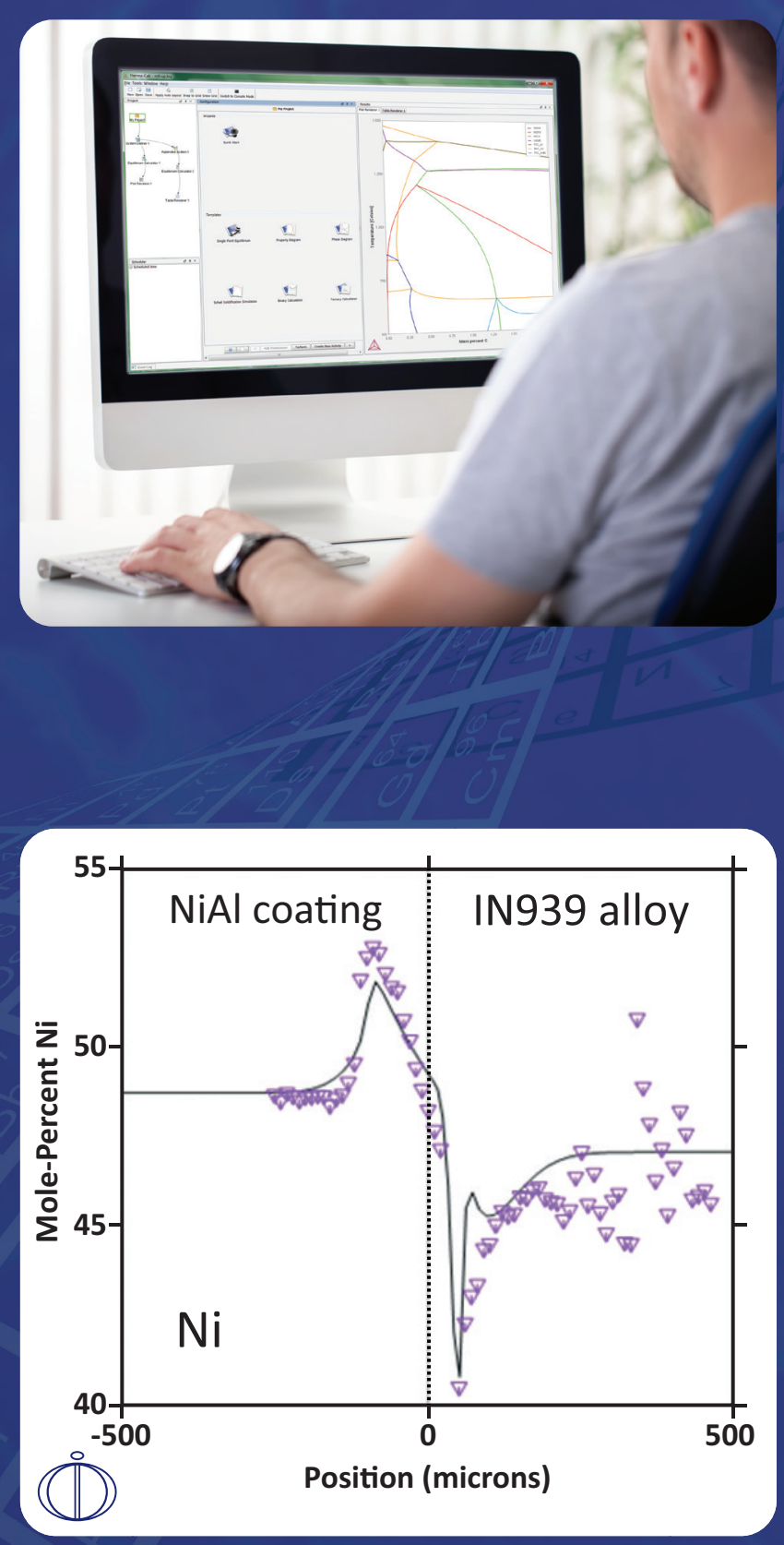

Diffusion in ordered phases

\section{Visit us at MRS Booth \#1030}

November 29 - December 1, 2016 Boston, Massachusetts 


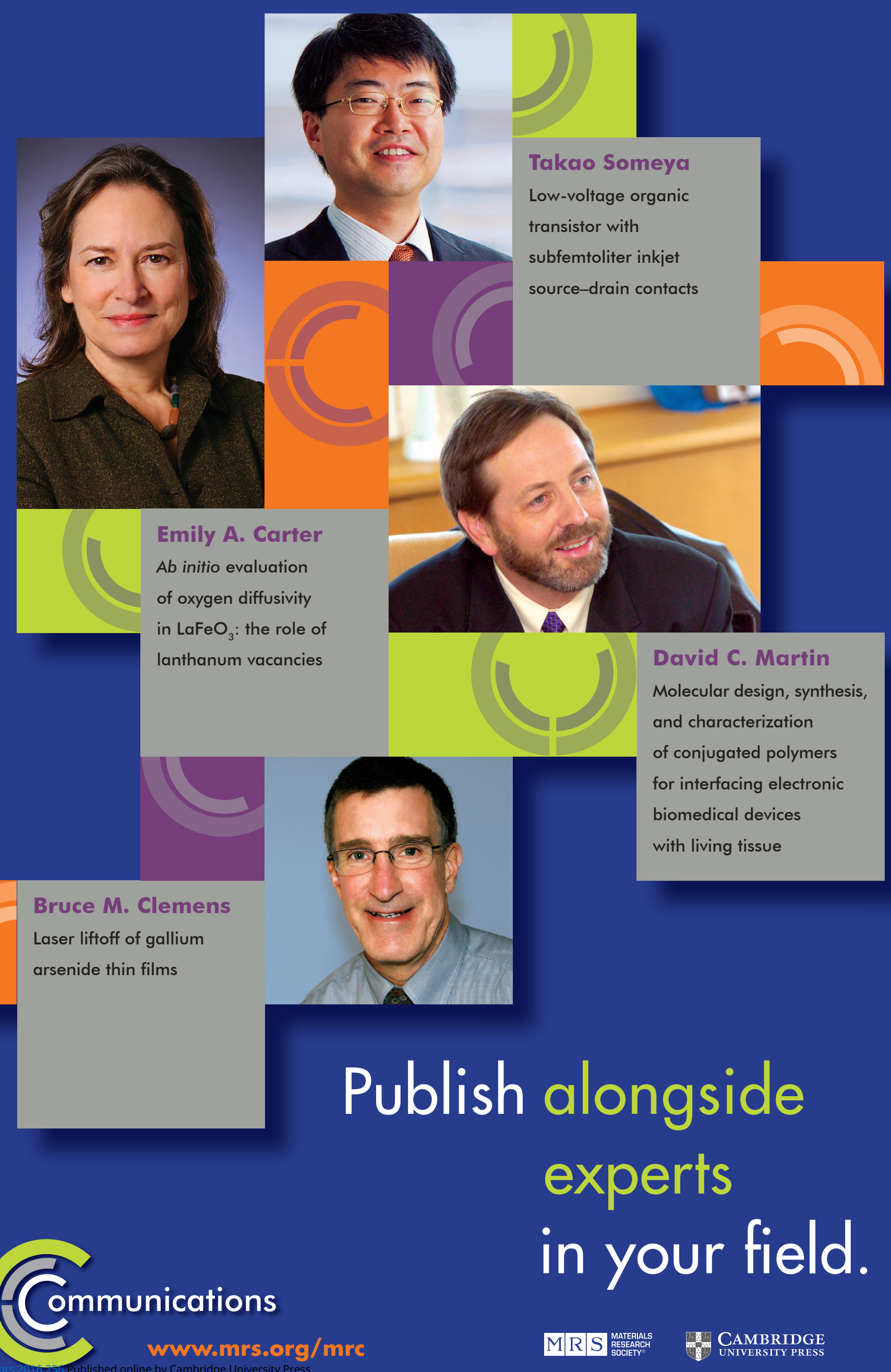

